\title{
Glucocorticoid-induced Changes in the Transcriptional Activity of Genes of the Innate and Adaptive Immune System in the Blood of Patients with Acute Urticaria
}

\author{
Alina Petruk ${ }^{1}$, Iryna Kamyshna ${ }^{2 *(i)}$, Mariia Shkilna ${ }^{1}$, Aleksandr Kamyshnyi ${ }^{3}$ iD \\ ${ }^{1}$ Department of Infectious Diseases and Epidemiology, Dermatology and Venereology, I. Horbachevsky Ternopil National Medical \\ University, Ternopil, Ukraine; ${ }^{2}$ Department of Medical Rehabilitation, I. Horbachevsky Ternopil National Medical University, Ternopil, \\ Ukraine; ${ }^{3}$ Department of Microbiology, Virology, and Immunology, I. Horbachevsky Ternopil National Medical University, Ternopil, Ukraine
}

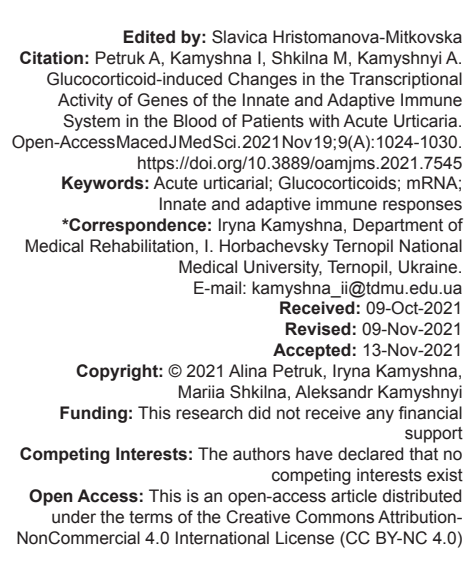

Introduction

Urticaria is considered a common dermatologic disorder typically manifesting in intensely itchy, wellcircumscribed, raised wheals that vary in size from some millimeters to several centimeters or even larger [1]. Urticaria that resolves within a period of fewer than 6 weeks is considered acute. Second-generation $\mathrm{H} 1$ antihistamines are chosen as first-line medications for the treatment of acute urticarial [2]. In some cases, they may be titrated up to two or even 4 times the usual dose to control symptoms. If symptoms are not sufficiently under control with secondgeneration $\mathrm{H} 1$ antihistamines, $\mathrm{H} 2$ antihistamines may be put in [3]. In severe cases, the following glucocorticoids (GCs) as prednisone or prednisolone $(0.5$ to $1 \mathrm{mg} / \mathrm{kg} /$ day) may be considered to add for 3-10 days to control symptoms [4]. The current EAACI/GA ${ }^{2}$ LEN/EDF/WAO health-care recommendations in 2018 proposed to regard the use of a short course of oral GCs for up to 10 days to reduce the continuity of symptoms in acute urticarial [5]. The theoretical mechanism of GCs does not inhibit mast cell degranulation but is probably activated by suppressing a range of stimulating inflammatory processes and T-cell activations [6]. The clinical effectiveness of GCs in the treatment of acute urticaria (AU) produces controversy [7]. In truth, short courses of oral GCs may cause significant adverse events [8].

Determination of the level of gene transcriptional activity is an essential index of the functional activity of cells [9], [10], [11], [12], [13]. Our previous studies show significant changes in the transcriptional profile and genetic variations in different pathological conditions [14], [15], [16], [17], [18], [19]. Changes in some genes expression of the innate and adaptive immune system play a vital role in the mechanisms of $A U$ development. On the other hand, the noted effect of GCs is their high ability to suppress the immune response. GCs can suppress the initiation of $\mathrm{T}$ cell responses by decreasing the antigen presentation, costimulation, and cytokine 
production functions of innate immune cells [20]. Many of the ultimate critical effects of GCs, however, are their direct actions on $T$ cells, primarily through transcription regulation, namely, elevated expression of immunoregulatory proteins, inhibitory receptors and apoptotic genes, and reduced expression of proinflammatory cytokines, costimulatory molecules, and cell cycle mediators [21]. Therefore, our work aimed to study the effect of the administered GCs on the transcriptional activity of the genes of the innate and adaptive immune system in the peripheral blood in patients with $\mathrm{AU}$.

\section{Materials and Methods}

\section{Participants and study design}

For our study, we isolated peripheral blood mononuclear cells from 12 patients with $A U$ who were administered standard treatment $\mathrm{H} 1$ - and $\mathrm{H} 2$-antihistamines (control group) and 12 patients with $\mathrm{AU}$ who received short-course therapy of GCs injected intramuscularly (dexamethasone, $4 \mathrm{mg} / \mathrm{ml}$, once a day, for 3 days). The diagnosis $\mathrm{AU}$ is based on the appearance of skin lesions. No laboratory reference standard is available. Diagnosis starts with a routine patient evaluation, which comprises a thorough history and physical examination, and the ruling out of severe systemic disease by basic laboratory tests. Physical examination of the patient includes a test for dermographism. Disease activity was determined using urticaria activity score (UAS). This simple scoring system is based on the assessment of key urticaria symptoms (wheals and pruritus). The 2018 EAACI/GA2LEN/EDF/NAO diagnosis guideline recommends using the UAS proposed in the previous version of the guideline to measure disease severity and monitor treatment results in daily practice [5]. The UAS assigns a score from 0 (no disease activity) to 3 (intense activity) for each of the two key urticaria symptoms, wheals and pruritus. The sum of the scores represents disease severity on a scale from 0 (minimum) to 6 (maximum). We excluded patients meeting the following criteria: Angioedema; anaphylaxis; the use of antihistamines or GCs within 7 days before the ED visit; and chronic urticaria.

We used a pathway-specific polymerase chain reaction (PCR) array (Human Innate and Adaptive Immune Responses RT2 Profiler PCR Array, QIAGEN, Germany) to identify and verify immune pathwayfocused genes expression in randomly selected 12 individuals from each group using real-time PCR due to the procedure described below.

\section{Experimental procedures}

RNA isolation

Total RNA was isolated from white blood cells using NucleoZOL (Macherey-Nagel, Germany), according to the manufacturer's instructions. NucleoZOL is designed for the isolation of total RNA (small and large RNA) in a single or separate fraction from a variety of sample materials, such as cells, tissue, and liquids of human or animal origin. White blood cells were lysed and homogenized in NucleoZOL reagent based on guanidinium thiocyanate and phenol.

\section{cDNA synthesis}

The RNA quality was determined and it was reverse transcribed. The concentration and quality of the isolated total RNA were determined on a NanoDrop spectrophotometer (Thermo Scientific ${ }^{\mathrm{TM}}$, USA). For the reverse transcription procedure with a cDNA conversion $\mathrm{RT}^{2}$ First Strand Kit (QIAGEN, Germany, Cat. no. 330401), RNA samples with the following parameters were selected: Ratio A260/A280 within the range of 1.8 2.2. The RT2 HT First Strand Kit procedure comprises two steps: Elimination of genomic DNA contamination and reverse transcription, which enable fast and easy handling of 96 RNA samples simultaneously. After genomic DNA elimination, the RNA sample undergoes reverse transcription with an RT master mix, as well as random hexamers and oligo-dT prime reverse transcription to capture more difficult-to-detect genes.

\section{PCR array}

The cDNA was then used with RT2 Profiler PCR Array (QIAGEN, Cat. no. PAHS- 052ZA) in combination with RTI SYBR $\circledast$ Green qPCR Mastermix (QIAGEN, Cat. no. 330504), following the complete RT2 Profiler PCR Array procedure (www.qiagen. com). Samples were assigned to control and study groups. Cycle threshold (CT) values were normalized based on an automatic selection from the full panel of reference genes. Any $\mathrm{Ct}$ value $>35$ was considered to be a negative call. The RT2 Profiler PCR Array data analysis software calculates the fold change based on the widely used and agreed upon $\Delta \Delta \mathrm{Ct}$ method. The data analysis web portal calculates fold change/ regulation using the delta-delta CT method, in which delta CT is calculated between the gene of interest and an average of reference genes housekeeping genes, followed by delta-delta CT calculations (delta CT [Test Group]-delta CT [Control Group]). Fold change is then calculated using a $2^{\wedge}$ (-delta-delta CT) formula. This data analysis report was exported from the QIAGEN web portal at GeneGlobe. The software allows defining the best reference genes for normalization.

\section{Statistical analysis of PCR array data}

The RT2 Profiler PCR Array Data Analysis software does not perform any statistical analysis beyond the calculation of $p$-values using a Student's t-test (twotailed distribution and equal variances between the two 
samples) based on the triplicate $2^{\wedge}(-\Delta \mathrm{CT})$ values for each gene in the experimental group compared to the control group. The Microarray Quality Control published results indicating that a ranked list of genes based on a fold change and such a p-value calculation was sufficient to demonstrate reproducible results across multiple microarrays and PCR arrays including the RT2 Profiler PCR Arrays.

\section{Ethical approval}

The ethical principles contained in the Declaration of Human Rights adopted in Helsinki, in 1975 , and revised in 2008, were fully respected in our study. The subjects enrolled, voluntarily participated in this study, and completed and signed written informed consent. The protocol of the study was approved by the local ethics committees of I. Horbachevsky Ternopil National Medical University.

\section{Results}

Applying the RT2 Profiler PCR Array Human Innate and Adaptive Immune Responses, we studied the expression of 84 genes involved in the immune response. Given the active involvement of both congenital and adaptive components of the immune system in the pathogenesis of $A U$, we initially used an array that includes genes from several functional groups such as (1) innate immunity genes, including pattern recognition receptors, (2) adaptive immunity genes, including Th1, Th2, Th17, and Treg cells markers, (3) T-cell activation, costimulation molecules, and transcriptional factors, (4) T-cells and B-cells dependent cytokines, (5) humoral immunity genes, and (6) inflammatory response genes and other.

The use of oral GCs as an adjunct to standard therapy with $\mathrm{H} 1$ - and $\mathrm{H} 2$-antihistamines did not significantly affect the nature of the clinical manifestations of $A U$, assessed by the UAS scale.
We had found that in patients with $A U$ during therapy with GCs, the expression in the blood of 17 genes out of the studied 84 genes of interest significantly changed (Table 1, Figures 1 and 2). Thus, adding GCs to standard therapy led to the transcriptional induction of the FOXP3 gene, which regulates the formation of Treg cells -13.68 -fold $(p=0.007291)$ and the main Treg-mediated suppressor cytokine interleukin (IL)-10 - 13.81-fold ( $p=0.018205$ ) compared to the control group. The administration of GCs led to a decrease in the transcriptional activity of the genes CCL5 (3.81-fold, $p=0.00006)$ and CXCL8 (9.06-fold, $p=0.013104)$ and a number of cytokines: Th1-mediated interferon gamma (IFNG) - by 24.69-fold ( $p=0.000112$ ), Th2-mediated IL2 and IL5 (3.79-fold, $p=0.013243$ and 18.89-fold, $p=$ 0.027027, respectively), Th17-mediated IL17A - 10.87fold $(p=0.039417)$, and systemic pro-inflammatory cytokines IL1B - 9.78-fold ( $p=0.005831)$ and, more pronounced, tumor necrosis factor (TNF) - 33.66-fold ( $p$ $=0.000071)$. GC-induced changes in the transcriptome also manifested with pronounced repression of the genes of costimulatory molecules CD40 - by 33.04-fold ( $p=$ $0.002482)$, CD80 (B7-1) - by 48.93-fold ( $p=0.021489$ ); transcriptional regulators of Th1-cells differentiation TBX21 (12.04-fold, $p=0.007368$ ) and STAT1 (3.15-fold, $p=0.025298)$, regulator of differentiation of Th17 cells RORC (14.45-fold, $p=0.000205)$, as well as the genes of NLRP3 - inflammasome (17.30-fold, $p=0.005008)$ and the transcription factor NFKB1 (6.30-fold, $p=$ $0.000154)$ compared to the control group.

Fold change $\left(2^{\wedge}[\right.$-Delta Delta CT] $)$ is the normalized gene expression $\left(2^{\wedge}[-\right.$ Delta $\left.C T]\right)$ in the test sample (AU + GCs, AU + GCs) divided the normalized gene expression $\left(2^{\wedge}[-\right.$ Delta $\left.\mathrm{CT}]\right)$ in the control sample $(A U)$. Fold regulation represents fold change results in a biologically meaningful way.

\section{Discussion}

Several previous studies have demonstrated that GCs combined with antihistamines may influence

Table 1: Changes in the transcriptional activity of immune response genes in patients with AU on the background of GCs therapy compared with patients with $\mathrm{AU}$

\begin{tabular}{|c|c|c|c|c|}
\hline Gene symbol & Description & $\begin{array}{l}\text { Fold change } \\
A U+G C s / \text { control group (AU) }\end{array}$ & $\frac{t \text {-test }}{p \text { value }}$ & $\begin{array}{l}\text { Fold regulation } \\
A U+G C s / \text { control group }(A U)\end{array}$ \\
\hline CCL5 & Chemokine (C-C motif) ligand 5 & 0.26 & 0.000060 & -3.81 \\
\hline CD40 & CD40 molecule, TNF receptor superfamily member 5 & 0.03 & 0.002482 & -33.04 \\
\hline CD80 & CD80 molecule & 0.02 & 0.021489 & -48.93 \\
\hline FOXP3 & Forkhead box P3 & 13.68 & 0.007291 & 13.68 \\
\hline IFNG & Interferon, gamma & 0.04 & 0.000112 & -24.69 \\
\hline IL10 & Interleukin 10 & 13.81 & 0.018205 & 13.81 \\
\hline IL17A & Interleukin 17A & 0.09 & 0.039417 & -10.87 \\
\hline IL1B & Interleukin 1, beta & 0.10 & 0.005831 & -9.78 \\
\hline IL2 & Interleukin 2 & 0.26 & 0.013243 & -3.79 \\
\hline IL5 & Interleukin 5 (colony-stimulating factor, eosinophil) & 0.05 & 0.027027 & -18.89 \\
\hline CXCL8 & Interleukin 8 & 0.11 & 0.013104 & -9.06 \\
\hline NFKB1 & Nuclear factor of kappa light polypeptide gene enhancer in B-cells 1 & 0.16 & 0.000154 & -6.30 \\
\hline NLRP3 & NLR family, pyrin domain containing 3 & 0.06 & 0.005008 & -17.30 \\
\hline RORC & RAR-related orphan receptor C & 0.07 & 0.000205 & -14.45 \\
\hline STAT1 & Signal transducer and activator of transcription 1 & 0.32 & 0.025298 & -3.15 \\
\hline TBX21 & T-box 21 & 0.08 & 0.007368 & -12.04 \\
\hline TNF & Tumor necrosis factor & 0.03 & 0.000071 & -33.66 \\
\hline
\end{tabular}




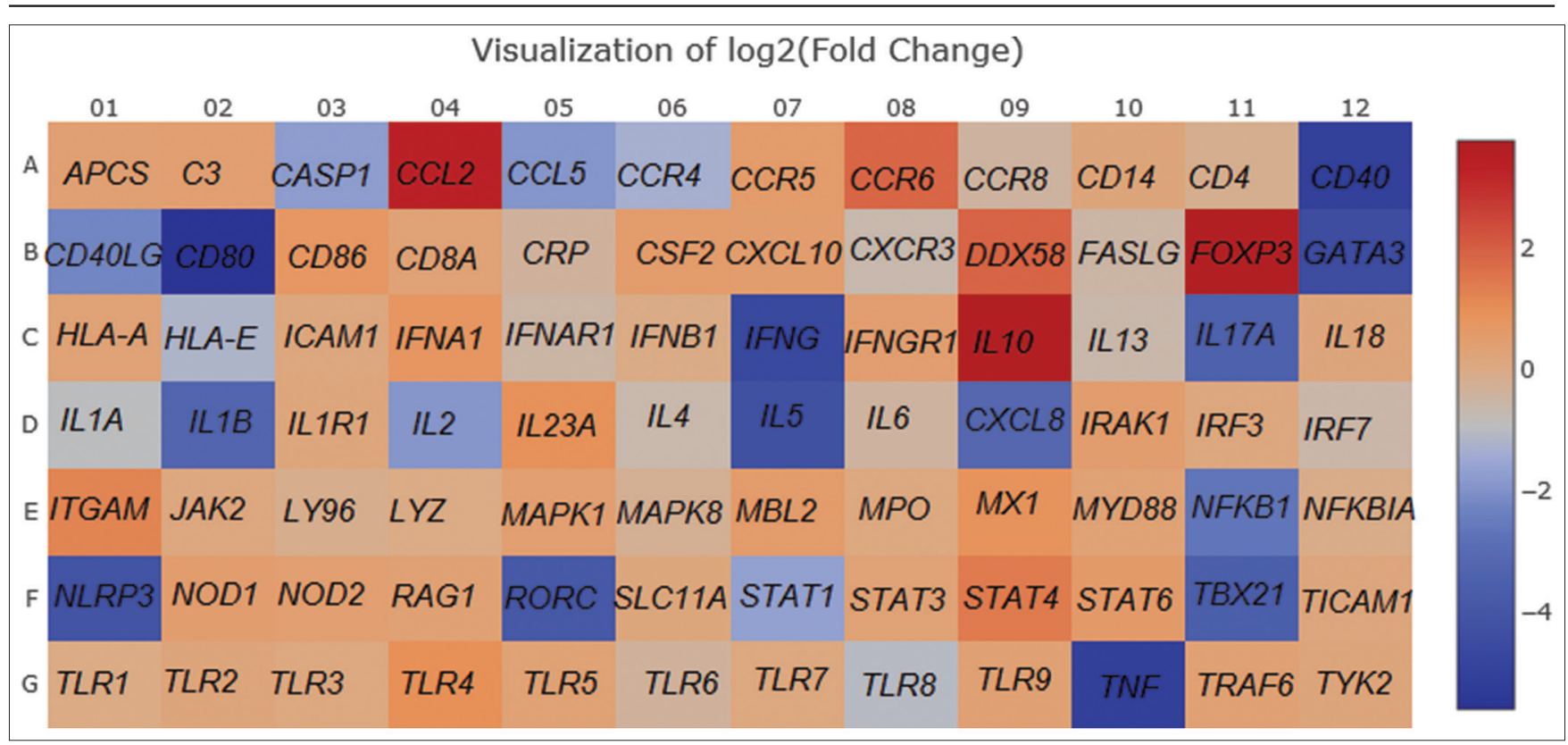

Figure 1: Heat map plot. Visualization of log2 (fold change) gene expression. Acute urticaria + glucocorticoids versus acute urticaria (control)

faster remission in AU patients [22]. Adding oral GCs are related to notable symptom improvement and lessened attack duration. Therefore, GCs are predominantly administered to emergency department (ED) patients with AU [23]. However, there are some inconsistent data regarding the effectiveness of GCs in the treatment of AU. A previous study by Barniol et al. (2018) of a 4-day course of prednisolone with antihistamines has not shown advancement in clinical response 2 days after attending ED [7]. A retrospective study of 2011 described $93 \%$ of 459 Italian patients visiting an ED for this condition who received GCs [23]. Another recent observational study

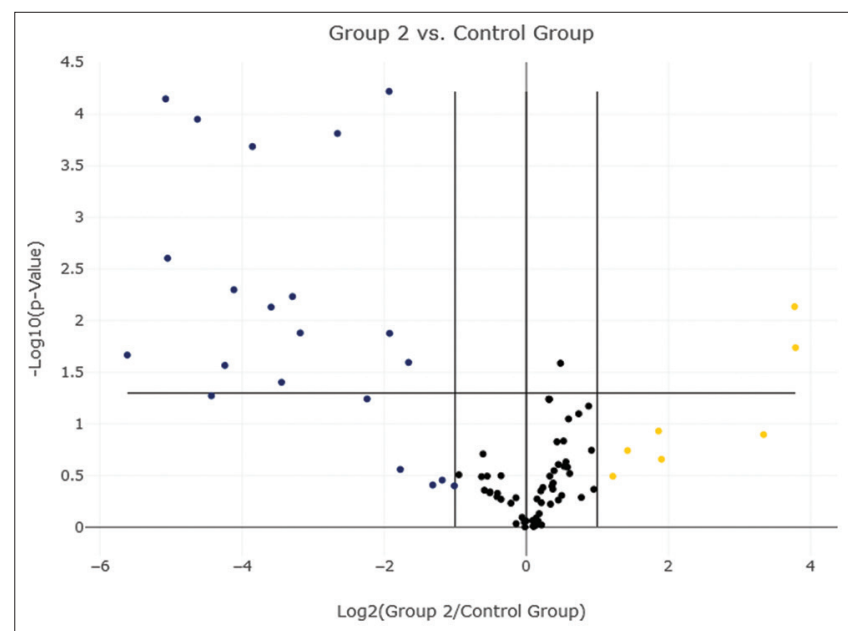

Figure 2: Volcano plot identifies significant gene expression changes by plotting the log2 of the fold changes in gene expression on the $X$-axis versus their statistical significance on the $Y$-axis. The center vertical line indicates unchanged gene expression, while the two outer vertical lines indicate the selected fold regulation threshold. The horizontal line indicates the selected p-value threshold. Genes with data points in the far upper left (downregulated, blue) and far upper right (upregulated, yellow) sections meet the selected fold regulation and p-value thresholds. Group 2 - acute urticaria+ glucocorticoids. Control group - acute urticaria in Canada reported frequent GCs use (48\% of 2701 ED visits) to treat allergic reactions or anaphylaxis, which had no significant benefit [24]. These data coincide with our outcomes on the absence of clinically significant changes in the course of $\mathrm{AU}$ when $\mathrm{GCs}$ are added to standard therapy. Furthermore, a recent study by Arga et al. (2021) did not favor adding GCs to the antihistamine in treatment for severe pruritus in patients with AU [25]. The authors summarize that using GCs as an adjunctive treatment is discouraged due to the lack of clinical benefits and possible side effects. A randomized study by Javaud et al. (2019) is still ongoing [26].

Given the uncertain clinical benefit of GCs, we focused on elucidating their effects on the transcriptional activity of immune response genes, which could provide a rationale in searching for more targeted therapies for such conditions. GCs can suppress the initiation of T-cell responses by decreasing the antigen presentation, costimulation, and cytokine production functions of innate immune cells [6]. However, the utmost vital effects of GCs are their immediate impact on $\mathrm{T}$ cells, mainly through regulation of transcription, namely, elevated expression of immune regulatory proteins, inhibitory receptors and apoptotic genes, and reduced expression of pro-inflammatory cytokines, costimulatory molecules, and cell cycle mediators [27]. The GCs receptors (GRs) directly bind with nuclear factor kappa B (NF-kB) and AP-1 family proteins to inhibit their transcriptional activity [28]. The outcome is the following: GCs suppress T-cell expression of costimulatory molecules (such as CD28), cytokines (IL2, IL-4, IL-5, IL-6, IL-8, TNF, and IFN $\gamma$ ), and chemokines (CCL3, CCL4, CCL5, CCL7, CCL8, CCL11, and CCL13) [29]. Furthermore, GCs upregulate coinhibitory molecules such as PD1, CTLA4, LAG3, and TIM3 [30]. The final result demonstrates the potent suppression of T-cell effector programs. 
All T-cells express GR, but different cells have different GC sensitivity. Thus, although the total impact of GC signaling is suppression of T-cell activation, differential suppression of subsets sufficiently suggests that GCs stimulate particular T-helper cell responses over others, namely, they force inhibition of Th1 cells, moderate inhibition of Th2 cells, and contribute permission for Th17 cell responses [6]. These investigation patterns are partly confirmed by our results. We observed transcriptional repression of Th1-cell differentiation regulators - TBX21 and STAT1, Th17 cells - RORC, as well as genes Th1-, Th2-, and Th17-dependent cytokines - IFNG, IL2, IL5, and IL17A.

GCs strongly inhibit Th1 cell responses. Inhibition of IL-12-induced STAT4 phosphorylation prevents its activation promoting transcriptional activity, and inhibiting STAT1 gene expression prevents IFN $\gamma$ signaling, with both effects controlling Th1 cell differentiation [31]. Furthermore, GCs inhibit the expression of T-bet (Tbx21) and IFNG genes, and the GR directly binds with T-bet protein, which prevents the expression of a $\mathrm{TH} 1$ cell transcriptional program [32]. GCs also suppress Th2 cell differentiation, but relatively less than Th1 cell differentiation. GCs have a bare effect on IL-4-induced STAT6 phosphorylation, but GC inhibits induction of GATA3, therefore may prevent expression of IL-4, IL-5, and IL-13 [33]. GCs upregulate T-cell expression of the IL-6 and transforming growth factor beta (TGF $\beta$ ) receptors and stimulate Th17 cell differentiation. Th17 cells are often refractory to GCs, which emerge partly due to increased expression of the GC exporting membrane channel multidrug resistance 1 [34]. Moreover, GCs increase RORyt expression and IL-17 production. Most commonly, GCs allow and even promote Th17 responses. The impacts of GCs on Th9, Th22, and T follicular helper cells are less marked and often conflicting [35].

Treg cell differentiation is certainly primed by GC signaling. Upregulation of TGF $\beta$ receptors, FOXP3 and IL-10, is consistent with elevated Treg cell differentiation and function [36]. GCs improvement of Treg cell function is a crucial mechanism by which endogenous GCs effect immunosuppression [37]. Our results also report the activation of the expression of the FOXP3 gene, which regulates the formation of Treg cells and the main Treg-mediated suppressor cytokine IL10, that, against the background of inhibition of the genes of costimulatory molecules CD40 and CD80, the transcription factor NFKB1, and systemic proinflammatory cytokines IL1B and TNF contributes to the prevalence of suppressor signals.

\section{Conclusions}

Thus, our study has shown that adding GCs to the standard treatment for $\mathrm{AU}$ have a pronounced immunosuppressive potential at the transcriptome level of the immune response genes in the blood; still, it does not have any noticeable clinical effect.

\section{References}

1. Pier J, Bingemann TA. Urticaria, angioedema, and anaphylaxis Pediatr Rev. 2020;41(6):283-92. http://doi.org/10.1542/ pir.2019-0056

2. Maurer M, Zuberbier T, Metz M. The classification, pathogenesis, diagnostic workup, and management of urticaria: An update. Handb Exp Pharmacol. 2021;2021:506. http://doi. org/10.1007/164_2021_506

3. Khan DA, Kocatürk E, Bauer A, Aygören-Pürsün E. What's new in the treatment of urticaria and angioedema. J Allergy Clin Immunol Pract. 2021;9(6):2170-84. http://doi.org/10.1016/j. jaip.2021.03.012 PMid:34112473

4. Yiğit RE, Cavkaytar O, Besli GE, Arga M. Do pediatric emergency physicians comply with guideline recommendations in management of patients with acute urticaria? Pediatr Emerg Care. 2021;37(8):407-412. http://doi.org/10.1097/ PEC.0000000000002327

PMid:34043307

5. Zuberbier T, Aberer W, Asero R, Latiff AH, Baker D, BallmerWeber $B$, et al. The EAACI/GA(2)LEN/EDF/WAO guideline for the definition, classification, diagnosis and management of urticaria. Allergy. 2018;73(7):1393-414. http://doi.org/10.1111/ all.13397

PMid:29336054

6. Taves MD, Ashwell JD. Glucocorticoids in T cell development, differentiation and function. Nat Rev Immunol. 2021;21(4):23343. http://doi.org/10.1038/s41577-020-00464-0

PMid:33149283

7. Barniol C, Dehours E, Mallet J, Houze-Cerfon $\mathrm{CH}$, Lauque $\mathrm{D}$, Charpentier S. Levocetirizine and prednisone are not superior to levocetirizine alone for the treatment of acute urticaria: A randomized double-blind clinical trial. Ann Emerg Med. 2018;71(1):125-31.e1. http://doi.org/10.1016/j. annemergmed.2017.03.006

PMid:28476259

8. Waljee AK, Rogers MA, Lin P, Singal AG, Stein JD, Marks RM, et al. Short termuse of oral corticosteroids and related harms among adults in the United States: Population based cohort study. BMJ. 2017;357:j1415. http://doi.org/10.1136/bmj.j1415 PMid:28404617

9. Bilous I, Pavlovych L, Krynytska I, Marushchak M, Kamyshnyi A Apoptosis and cell cycle pathway-focused genes expression analysis in patients with different forms of thyroid pathology. Open Access Maced J Med Sci. 2020;8(B):784-92. https://doi. org/10.3889/oamjms.2020.4760

10. Bilous II, Korda MM, Krynytska IY, Kamyshnyi AM. Nerve impulse transmission pathway-focused genes expression analysis in patients with primary hypothyroidism and autoimmune thyroiditis. Endocr Regul. 2020;54(2):109-18. https://doi.org/10.2478/enr-2020-0013 PMid:32597152

11. Bilous II, Pavlovych LL, Kamyshnyi AM. Primary hypothyroidism and autoimmune thyroiditis alter the transcriptional activity of genes regulating neurogenesis in the blood of patients. Endocr Regul. 2021;55(1):5-15. https://doi.org/10.2478/enr-2021-0002 
PMid:33600668

12. Kamyshna II, Pavlovych LB, Maslyanko VA, Kamyshnyi AM. Analysis of the transcriptional activity of genes of neuropeptides and their receptors in the blood of patients with thyroid pathology. J Med Life. 2021;14(2):243-9. https://doi.org/10.25122/ jml-2020-0183

PMid:34104248

13. Kamyshna I, Kamyshnyi A. Transcriptional activity of neurotrophins genes and their receptors in the peripheral blood in patients with thyroid diseases in Bukovinian population of Ukraine. Open Access Maced J Med Sci. 2021;9(A):208-16. https://doi.org/10.3889/oamjms.2021.6037

14. Kamyshna I, Pavlovych L, Kamyshnyi A. Association between serum brain-derived neurotrophic factor and 25-OH Vitamin D levels with Vitamin D receptors gene polymorphism (rs2228570) in patients with autoimmune thyroiditis and hypothyroidism. Open Access Maced J Med Sci. 2021;9(A):659-64. https://doi. org/10.3889/oamjms.2021.6631

15. Kamyshna I, Pavlovych L, Malyk I, Kamyshnyi A. 25-OH Vitamin D blood serum linkage with VDR gene polymorphism (rs2228570) in thyroid pathology patients in the West-Ukrainian population. J Med Life. 2021;14(4):549-56. https://doi. org/10.25122/jml-2021-0101

PMid:34621381

16. Putilin DA, Evchenko SY, Fedoniuk LY, Tokarskyy OS, Kamyshny OM, Migenko LM, et al. The influence of metformin to the transcriptional activity of the mTOR and FOX3 genes in parapancreatic adipose tissue of streptozotocin-induced diabetic rats. J Med Life. 2020;13(1):50-5. https://doi.org/10.25122/ jml-2020-0029

PMid:32341701

17. Degen AS, Krynytska IY, Kamyshnyi AM. Changes in the transcriptional activity of the entero-insular axis genes in streptozotocin-induced diabetes and after the administration of TNF- $\alpha$ non-selective blockers. Endocr Regul. 2020;54(3):16071. https://doi.org/10.2478/enr-2020-0019

PMid:32857721

18. Nosulenko IS, Voskoboynik OY, Berest GG, Safronyuk SL, Kovalenko SI, Kamyshnyi OM, et al. Synthesis and antimicrobial activity of 6-thioxo-6,7-dihydro-2H-[1,2,4]triazino[2,3-c]quinazolin-2-one derivatives. Sci Pharm. 2014;82(3):483-500. https://doi.org/10.3797/scipharm.1402-10

PMid:25853063

19. Lyubomirskaya ES, Kamyshnyi AM, Krut YY, Smiianov VA, Fedoniuk LY, Romanyuk LB, et al. SNPs and transcriptional activity of genes of innate and adaptive immunity at the maternal-fetal interface in woman with preterm labour, associated with preterm premature rupture of membranes. Wiad Lek. 2020;73(1):25-30.

PMid:32124801

20. Quatrini L, Ricci B, Ciancaglini C, Tumino N, Moretta L. Regulation of the immune system development by glucocorticoids and sex hormones. Front Immunol. 2021;12:672853. https://doi. org/10.3389/fimmu.2021.672853

PMid:34248954

21. Shimba A, Ikuta K. Control of immunity by glucocorticoids in health and disease. Semin Immunopathol. 2020;42(6):669-80. https://doi.org/10.1007/s00281-020-00827-8

PMid:33219395

22. Pollack CV Jr., Romano TJ. Outpatient management of acute urticaria: the role of prednisone. Ann Emerg Med. 1995;26(5):54751. https://doi.org/10.1016/s0196-0644(95)70002-1

PMid:7486360

23. Losappio L, Heffler E, Bussolino C, Cannito CD, Carpentiere R, Raie $A$, et al. Acute urticaria presenting in the emergency room of a general hospital. Eur J Intern Med. 2014;25(2):147-50. https://doi.org/10.1016/j.ejim.2013.11.003

PMid:24275113

24. Grunau BE, Wiens MO, Rowe BH, McKay R, Li J, Yi TW, et al. Emergency department corticosteroid use for allergy or anaphylaxis is not associated with decreased relapses. Ann Emerg Med. 2015;66(4):381-9. https://doi.org/10.1016/j. annemergmed.2015.03.003 PMid:25820033

25. Arga M, Cavkaytar Ö, Emeksiz HC. A randomized controlled trial of adding intravenous corticosteroids to $\mathrm{H} 1$ antihistamines in patients with acute urticaria. Am J Emerg Med. 2021;45:5923. https://doi.org/10.1016/j.ajem.2020.12.038

26. Javaud N, Soria A, Maignan M, Martin L, Descamps V, Fain O, et al. Glucocorticoids for acute urticaria: Study protocol for a double-blind non-inferiority randomised controlled trial. BMJ Open. 2019;9(8):e027431. https://doi.org/10.1136/bmjopen-2018-027431 PMid:31439599

27. Tian J, Zhang B, Rui K, Wang S. The role of GITR/GITRL Interaction in autoimmune diseases. Front Immunol. 2020;11:588682. https://doi.org/10.3389/fimmu.2020.588682 PMid:33163004

28. Motavalli R, Majidi T, Pourlak T, Abediazar S, Shoja MM, Vahed SZ, et al. The clinical significance of the glucocorticoid receptors: Genetics and epigenetics. J Steroid Biochem Mol Biol. 2021;213:105952. https://doi.org/10.1016/j.jsbmb.2021.105952 PMid:34274458

29. Li Z, Trakooljul N, Hadlich F, Ponsuksili S, Wimmers K, Murani E. Transcriptome analysis of porcine PBMCs reveals lipopolysaccharide-induced immunomodulatory responses and crosstalk of immune and glucocorticoid receptor signaling. Virulence. 2021;12(1):1808-24. https://doi.org/10.1080/215055 94.2021 .1948276

PMid:34288827

30. Ramos-Casals M, Brahmer JR, Callahan MK, FloresChávez A, Keegan N, Khamashta MA, et al. Immune-related adverse events of checkpoint inhibitors. Nat Rev Dis Primers. 2020;6(1):38. https://doi.org/10.1038/s41572-020-0160-6 PMid:32382051

31. Strehl C, Ehlers L, Gaber T, Buttgereit F. Glucocorticoidsall-rounders tackling the versatile players of the immune system. Front Immunol. 2019;10:1744. https://doi.org/10.3389/ fimmu.2019.01744

PMid:31396235

32. Xia C, Liu C, Liu Y, Long Y, Xu L, Liu C. Increased circulating Th1 and Tfh1 cell numbers are associated with disease activity in glucocorticoid-treated patients with IgG4-related disease. J Immunol Res. 2020;2020:3757015. https://doi. org/10.1155/2020/3757015

PMid:33313326

33. Luchak A, Solomon LA, Kanagalingam T, Vijeyakumaran M, Rowe $\mathrm{BH}$, Cameron L. Comparative efficacy of glucocorticoid receptor agonists on Th2 cell function and attenuation by progesterone. BMC Immunol. 2020;21(1):54. https://doi. org/10.1186/s12865-020-00383-8

PMid:33076829

34. de Castro Kroner J, Knoke K, Kofler DM, Steiger J, Fabri M. Glucocorticoids promote intrinsic human TH17 differentiation. J Allergy Clin Immunol. 2018;142(5):1669-73.e11. https://doi. org/10.1016/j.jaci.2018.07.019 PMid:30092286

35. Oja AE, Brasser G, Slot E, van Lier RA, Pascutti MF, Nolte MA GITR shapes humoral immunity by controlling the balance between follicular $T$ helper cells and regulatory $T$ follicular cells. Immunol Lett. 2020;222:73-79. https://doi.org/10.1016/j. 
imlet.2020.03.008

36. Rocamora-Reverte L, Tuzlak S, von Raffay L, Tisch M, Fiegl H, Drach M, et al. Glucocorticoid receptor-deficient Foxp3+ regulatory $T$ cells fail to control experimental inflammatory bowel disease. Front Immunol. 2019;10:472. https://doi.org/10.3389/fimmu.2019.00472 PMid:30936873
37. Kim D, Nguyen QT, Lee J, Lee SH, Janocha A, Kim S, et al Anti-inflammatory roles of glucocorticoids are mediated by Foxp3 ${ }^{+}$regulatory T cells via a miR-342-dependent mechanism. Immunity. 2020;53(3):581-96.e5. https://doi.org/10.1016/j. immuni.2020.07.002

PMid:32707034 